\title{
A Topology Optimization Method for Stochastic Lattice Structures
}

\author{
Filippo Cucinotta, Marcello Raffaele ${ }^{(凶)}$, and Fabio Salmeri \\ Department of Engineering, University of Messina, Contrada Di Dio (S. Agata), \\ 98166 Messina, Italy \\ fsalmeri@unime.it
}

\begin{abstract}
Stochastic lattice structures are very powerful solutions for filling three-dimensional spaces using a generative algorithm. They are suitable for 3D printing and are well appropriate to structural optimization and mass distribution, allowing for high-performance and low-weight structures. The paper shows a method, developed in the Rhino-Grasshopper environment, to distribute lattice structures until a goal is achieved, e.g. the reduction of the weight, the harmonization of the stresses or the limitation of the strain. As case study, a cantilever beam made of Titan alloy, by means of SLS technology has been optimized. The results of the work show the potentiality of the methodology, with a very performing structure and low computational efforts.
\end{abstract}

Keywords: Topology Optimization · Additive Manufacturing · Mechanical design · Lattice structures

\section{Introduction}

Topology Optimization (TO) is a very powerful tool [1] and it allows to obtain lightweight structures, optimizing one or more parameters [2]. Recently, thanks to the rapid development of the Additive Manufacturing (AM) technologies, also TO has had a rapid increase in interest and application [3]. The main fields range from biomedical $[4,5]$ to sports [6], automotive [7] and aerospace [8].

In 2019, Cucinotta et al. proposed a 2D TO method based on a new algorithm developed in the Rhinoceros-Grasshopper environment (grasshopper3d.com) [9, 10] based on a Voronoi tessellation. In this work, the authors present an important evolution of that method, with a 3D-volume application and the use of a reticular structure, instead of the hollowing. In this case the generated structure is lattice, based on points, called seeds, distributed in a stochastic way or with a distribution law.

The method is oriented for a Selective Laser Sintering (SLS) AM technology, or similar. These techniques consist in the sintering of metal powders with the energy supply coming from a laser light $[6,10]$. 


\section{Materials and Methods}

\subsection{The Algorithm}

The algorithm has been developed in the Rhinoceros - Grasshopper environment. The Grasshopper is a visual programming language that allows to parametrize the drawing tools of the Rhinoceros CAD (Fig. 1). The first step of the algorithm is the filling of the regions that are to be optimized with the seeds. Each seed is the point where the lattices will connect to each other. It is possible to decide the number and the distribution of the seeds, that can be uniform or not. In the second step, the seeds are interconnected by linear prismatic elements. In this phase it is possible to decide a limit of a number of connections for each node and the maximum and minimum length limits of the connectors. Obviously, by increasing the number and the limits, the number of connectors that make up the lattice structure increases. At the end of each stage, the algorithm exports a ready-to-use universal .STP file.

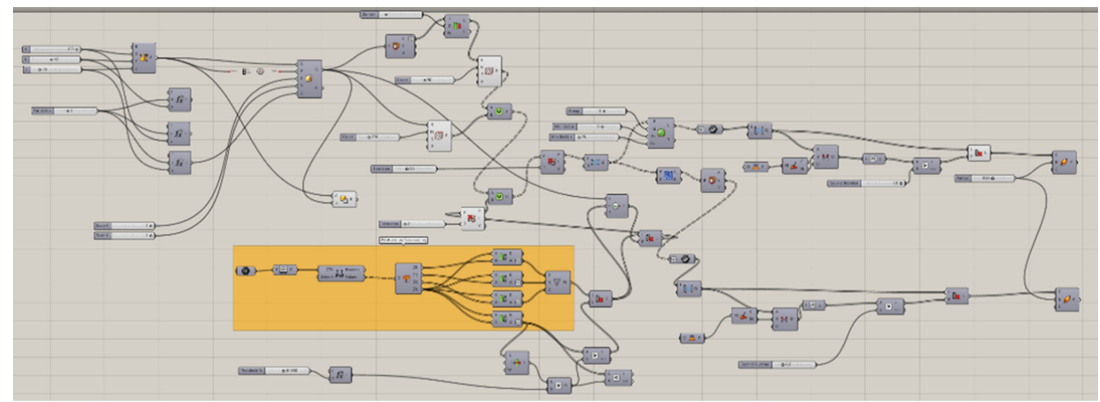

Fig. 1. The algorithm on the Grasshopper canvas

\subsection{The Case Study}

The case study is a monolithic cantilever beam, with a fixed constrain in a side and the load on the opposite side, that is optimized only in the core volume, fixing the upper and a lower face with a constant thickness. In this way, the result, is a sandwich panel [12] with all the potentiality in terms of weight and stress of this kind of structures [13, 14]. The objective of the TO has been set as the reduction of the global weight of the system, until a set stress threshold is reached (in this case set as $70 \%$ of the yield stress, i.e. about $600 \mathrm{MPa}$ ). The component is a 100 (length) $\times 50$ (width) $\times 13$ (thickness) $\mathrm{mm}$ cantilever beam, with a fixed constrain in a side, and a vertical force $(2 \mathrm{kN})$, distributed on the edge, on the opposite side. At the iteration 0 , the beam was monolithic. After that iteration, at each subsequent step, the algorithm populates with seeds the volume between the upper and lower face, realizing a sandwich. The thickness of the two skin was fixed (in the case study $3 \mathrm{~mm}$ ). The seeds have been increasingly populated, keeping the points that reach a stress threshold, set at $70 \%$ of the yield point of the material, plus a random quota. The random quota can be distributed uniformly, as in the case of this 
work, or non-uniformly with an ad hoc distribution law. For each seed, the algorithm connects the nearest 5 seeds with a beam, provided they are neither longer nor shorter than certain limits. Each beam was imposed with a circular section and a fixed diameter of $0.5 \mathrm{~mm}$.

For this work the Ti-6Al-4V ELI alloy has been used hypothesizing an AM process in SLS technology [11]. This type of material is used in various industrial sectors, in relation to its good mechanical properties and in the biomedical field in consequence of its biocompatibility [14].

The Finite Element Analysis (FEA) was performed using the Nastran solver within Siemens NX 1859. The choice of mesh was a structured hexahedral grid with size of $1 \mathrm{~mm}$, in the monolithic component and in the skins, and beams elements for the lattice structure. A linear static analysis was performed using a Nastran SOL 101. To be sure that the boundary conditions were always the same in each simulation, fixed selection boxes have been created.

\section{Results and Discussion}

The Fig. 2 shows the FEA results at the last step (with 1000 seeds). It is possible to observe that, if the skins are linearly loaded, as expected, the beams are more or less uniformly loaded, because the number of seeds change in function of the stress.

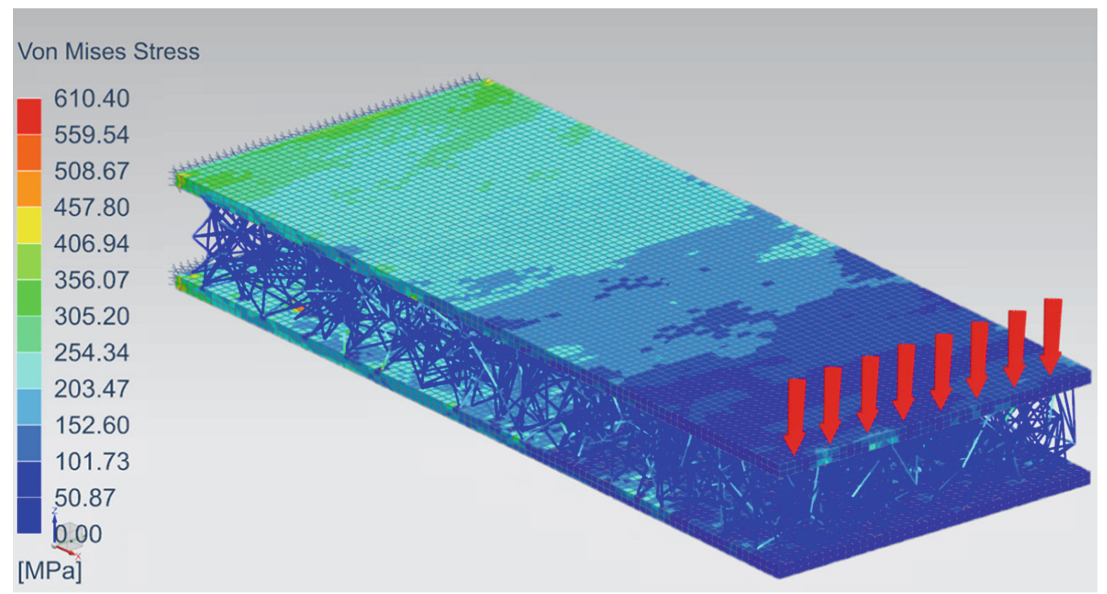

Fig. 2. The maximum von Mises equivalent stress on the FEA at the last step. The distributed force is of $2 \mathrm{kN}$. The constrain is fixed on the opposite side of the force.

As the number of seeds increases, the number of beams increases and consequently the structure becomes more robust but also weightier (Fig. 3). To test the effectiveness of the algorithm, many population cycles were carried out until the maximum stress value stabilized without producing significant advantages. At that point, the weight/stress ratio grows. 


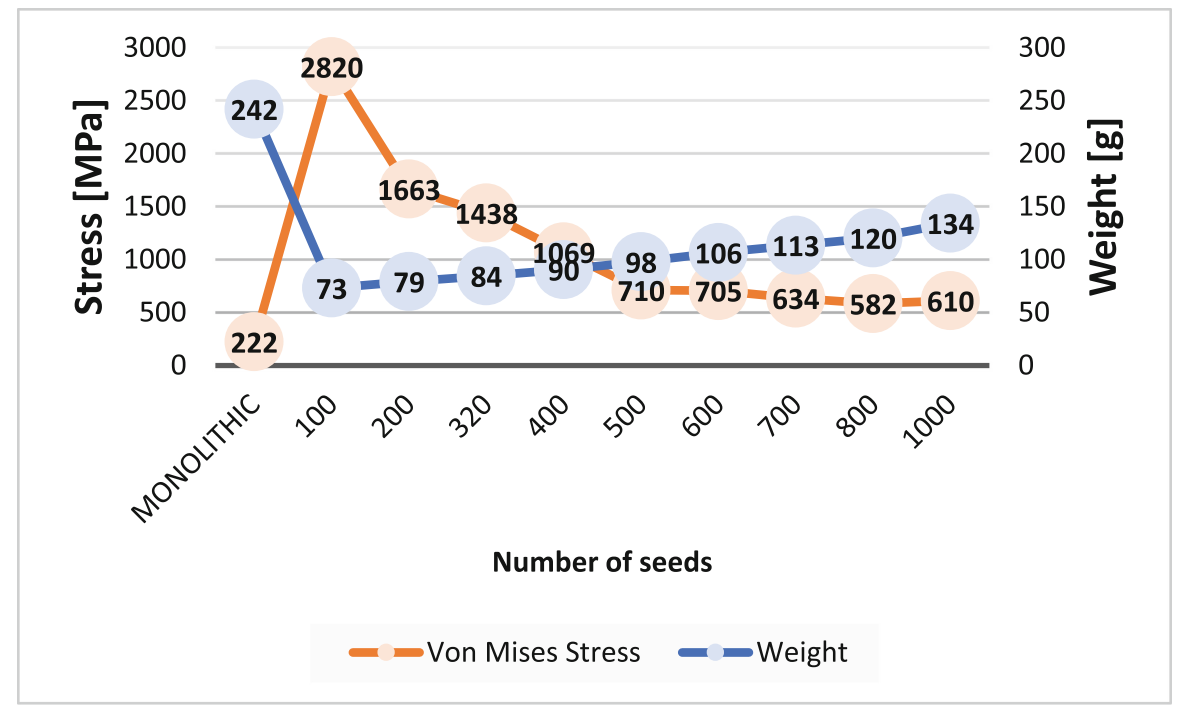

Fig. 3. The trend of stress and weight increasing the number of seeds

At the end of the optimization, the component reached the fixed allowable stress $(600 \mathrm{MPa})$ with a weight reduction of $50 \%$ with 800 seeds and about 2700 beams.

The workstation used for running the algorithm was equipped with an Intel Core I78700 CPU with 16 GB of RAM and a nVidia Quadro P5000 16 GB. The computational time requested by the algorithm was about of $60 \mathrm{~s}$ for each CAD reconstruction, showing the high performance of the method also in terms of computational resources.

\section{Conclusions}

In the paper a novel 3D optimization method, based on a mix of random and highstress points, have been presented. The method is based on a stochastic lattice structure inside two, or more, monolithic walls. The algorithm has been developed inside the Rhinoceros-Grasshopper environment that allows to program and parametrise the CAD commands.

As case study a simple cantilever beam has been choose. The analysis shows the different effects, in terms of weight and stress, changing the number of seeds necessary for the construction of the stochastic lattice structure.

The method showed high potentialities with a drastic weight reduction (up to $50 \%$ ) and very good stress performance, with a very low computational effort. Furthermore, the stochastic structure ensures good performance even when real loads differ significantly from design loads.

\section{References}

1. Sigmund, O., Maute, K.: Topology optimization approaches. Struct. Multidiscip. Optim. 48, 1031-1055 (2013). https://doi.org/10.1007/s00158-013-0978-6 
2. Barone, S., Cucinotta, F., Sfravara, F.: A comparative life cycle assessment of utility poles manufactured with different materials and dimensions (2017). https://doi.org/10.1007/9783-319-45781-9_10

3. Gardan, J.: Additive manufacturing technologies: state of the art and trends. Int. J. Prod. Res. 54, 3118-3132 (2016). https://doi.org/10.1080/00207543.2015.1115909

4. Cucinotta, F., Guglielmino, E., Longo, G., Risitano, G., Santonocito, D., Sfravara, F.: Topology optimization additive manufacturing-oriented for a biomedical application. Adv. Mech. Des. Eng. Manuf. II (2019). https://doi.org/10.1007/978-3-030-12346-8_18

5. Singh, S., Ramakrishna, S.: Biomedical applications of additive manufacturing: present and future. Curr. Opin. Biomed. Eng. 2, 105-115 (2017). https://doi.org/10.1016/j.cobme.2017. 05.006

6. Graziosi, S., Rosa, F., Casati, R., Solarino, P., Vedani, M., Bordegoni, M.: Designing for metal additive manufacturing: a case study in the professional sports equipment field. Procedia Manuf. 11, 1544-1551 (2017). https://doi.org/10.1016/j.promfg.2017.07.288

7. Reddy, K.S.N., Maranan, V., Simpson, T.W., Palmer, T., Dickman, C.J.: Application of topology optimization and design for additive manufacturing guidelines on an automotive component (2016). https://doi.org/10.1115/DETC2016-59719

8. Zhu, J.-H., Zhang, W.-H., Xia, L.: Topology optimization in aircraft and aerospace structures design. Arch. Comput. Methods Eng. 23, 595-622 (2016). https://doi.org/10.1007/s11831015-9151-2

9. Cucinotta, F., Raffaele, M., Salmeri, F.: A stress-based topology optimization method by a Voronoi tessellation additive manufacturing oriented. Int. J. Adv. Manuf. Technol. 102 (2019). https://doi.org/https://doi.org/10.1007/s00170-019-03676-4

10. Cucinotta, F., Raffaele, M., Salmeri, F.: A Topology Optimization of a Motorsport Safety Device. Springer, Heidelberg (2020). https://doi.org/10.1007/978-3-030-31154-4_34

11. Fotovvati, B., Namdari, N., Dehghanghadikolaei, A.: Fatigue performance of selective laser melted Ti6Al4V components: state of the art. Mater. Res. Express. 6, 14 (2019). https://doi. org/10.1088/2053-1591/aae10e

12. Cucinotta, F., Sfravara, F., Neri, P., Razionale, A.: Composite sandwich impact response: experimental and numerical analysis. Frat. ed Integrita Strutt. 13, 367-382 (2019). https:// doi.org/10.3221/IGF-ESIS.47.27

13. Cucinotta, F., Paoli, A., Risitano, G., Sfravara, F.: Optical measurements and experimental investigations in repeated low-energy impacts in powerboat sandwich composites. Proc. Inst. Mech. Eng. Part M J. Eng. Marit. Environ. (2017). https://doi.org/10.1177/147509021772 0619

14. Cucinotta, F., Guglielmino, E., Risitano, G., Sfravara, F.: Assessment of damage evolution in sandwich composite material subjected to repeated impacts by means optical measurements. Procedia Struct. Integr. 2, 3660-3667 (2016). https://doi.org/10.1016/j.prostr.2016.06.455 
Open Access This chapter is licensed under the terms of the Creative Commons Attribution 4.0 International License (http://creativecommons.org/licenses/by/4.0/), which permits use, sharing, adaptation, distribution and reproduction in any medium or format, as long as you give appropriate credit to the original author(s) and the source, provide a link to the Creative Commons license and indicate if changes were made.

The images or other third party material in this chapter are included in the chapter's Creative Commons license, unless indicated otherwise in a credit line to the material. If material is not included in the chapter's Creative Commons license and your intended use is not permitted by statutory regulation or exceeds the permitted use, you will need to obtain permission directly from the copyright holder.

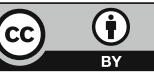

